\title{
ESTADO DO CONHECIMENTO DA EDUCAÇÃO PROFISSIONAL E TECNOLÓGICA NA PÓS-GRADUAÇÃO, STRICTO SENSU, EM SERVIÇO SOCIAL, DA REGIÃO CENTRO- OESTE
}

\author{
J. N. E. CANTUÁRIO \\ Instituto Federal de Educação Ciência e Tecnologia Goiano - Campus Urutai \\ janaina.cantuario@ifgoiano.edu.br
}

Artigo submetido em outubro/2015 e aceito em dezembro/2015

DOI: 10.15628/rbept.2015.3549

\section{RESUMO}

Este artigo compreende a investigação da produção dos cursos da pós-graduação, stricto sensu, de serviço social da região Centro-Oeste sobre a temática da educação profissional e tecnológica. As ênfases analíticas sistematizadas evidenciam as conexões entre a reestruturação produtiva e a organização do trabalho no campo da educação profissional e tecnológica; a educação e dualidade estrutural e as políticas sociais e assistência estudantil. $\mathrm{O}$ estudo confirma que a temática educação profissional e tecnológica ganha relevância no serviço social com as transformações e recomposições do capitalismo e as correlatas mudanças na organização do trabalho, período que coincide com novas configurações nas políticas educacionais do Estado brasileiro, a expansão da pós-graduação no Brasil e o desenvolvimento de um novo campo de estudos, pesquisa e produção de conhecimento, que, de maneira mais geral, trata da relação entre o sistema produtivo e o sistema educativo.

PALAVRAS-CHAVE: educação profissional e tecnológica, trabalho, produção de conhecimento, serviço social, estado do conhecimento.

\section{STATE OF KNOWLEDGE OF PROFESSIONAL AND TECHNOLOGICAL EDUCATION SYSTEM IN POSTGRADUATE COURSES, STRICTO SENSU, OF SOCIAL SERVICE IN THE CENTRAL-WEST REGION OF BRAZIL}

\begin{abstract}
This article comprises the research of the production of postgraduate courses, stricto sensu, of Social Service in the Central-West Region of Brazil, about the professional and technological education system. The systematic analytical emphases highlight the connections between productive restructuring and work organization in the field of vocational and technological education; education and structural duality and social and student assistance policies. The study confirms that the thematic professional and technological education becomes
\end{abstract}

relevant in social work with the changes and rearrangements of capitalism and the related changes in the organization of work, a period that coincides with new settings in the Brazilian state educational policies, graduate expansion in Brazil and the development of a new field of study, research and knowledge production, which, more generally, deals with the relationship between the productive system and the education system as essential mediation in the relationship between work and education.

KEYWORDS: Professional and technological education, work, Knowledge production, social service postgraduation, state of knowledge. 


\section{INTRODUÇÃO}

Partindo da necessidade de se conhecer, o "estado do conhecimento ${ }^{1 "}$ da educação profissional e tecnológica na pós-graduação, stricto sensu, em serviço social, situadas na região Centro-Oeste, objetiva-se com este artigo contribuir com os estudos e aprofundamento das pesquisas e da reflexão teórica na área. Posto isto, neste artigo é realizado um breve perfil da pósgraduação, stricto sensu, em serviço social no Brasil e região Centro-Oeste, bem como são desenvolvidas aproximações analíticas, decorrentes do balanço nas dissertações dos programas de pós-graduação, especificamente relacionadas à temática educação profissional e tecnológica.

\section{PERFIL DA PÓS-GRADUAÇÃO, STRICTO SENSU, EM SERVIÇO SOCIAL NO BRASIL}

De acordo com a Coordenação de Aperfeiçoamento de Pessoal de Nível Superior (Capes, 2013, p. 3), a implantação da pós-graduação, stricto sensu, em Serviço Social no Brasil tem quatro décadas. Os cursos de mestrado pioneiros foram os das Instituições de Ensino Superior (IES), da região Sudeste: Pontifícia Universidade Católica do Rio de Janeiro (PUC-RJ) e Pontifícia Universidade Católica de São Paulo (PUC-SP), em 1972 e Universidade Federal do Rio de Janeiro (UFRJ), em 1976. Ainda na década de 1970, verificou-se a expansão da pós-graduação para a região Sul, com a criação do mestrado na Pontifícia Universidade Católica do Rio Grande do Sul (PUC-RS), em 1977 e para a região Nordeste, com o mestrado da Universidade Federal da Paraíba (UFPB), em 1978, e da Universidade Federal de Pernambuco (UFPE), em 1979. Portanto, seis programas foram criados na década de 1970. Já em 1981, foi criado na PUC-SP, o primeiro curso de doutorado, constituindo-se pioneiro na América Latina. Contudo, nessa década, não foram criados outros programas de pós-graduação na respectiva área.

A expansão da pós-graduação, stricto sensu, em serviço social, foi retomada nos anos 1990, com a criação de cinco novos programas, dos quais destaca-se a criação do mestrado na Universidade de Brasília (UnB), em 1990, estendendo-a para a região Centro-Oeste. Entre os anos 2000-2012, registra-se o maior impulso da área no país com a criação de vinte novos programas.

Atualmente, a pós-graduação em serviço social, de acordo com os dados da CAPES, referentes ao ano de $2013,{ }^{2}$ possui 31 programas de pós-graduação, dos quais quinze possuem cursos de doutorado e mestrado e dezesseis ofertam cursos de mestrado acadêmico, totalizando a oferta de 46 cursos na área. Como evidenciado na configuração metodológica, o objeto deste estudo são as dissertações dos três programas de pós-graduação, stricto sensu, em serviço social, situados na região Centro-Oeste, sendo dois programas vinculados há Instituições de Ensino Superior (IES) públicas (UnB e UFMT) e um em IES comunitárias (PUC Goiás). Em relação à área básica dois programas são em Política Social (UnB e UFMT) e um em Serviço Social (PUC Goiás).

\footnotetext{
${ }^{1}$ Segundo Romanowski e Ens (2006, p. 40) o termo estado da arte resulta de uma tradução literal do Inglês, e, tem por objetivo realizar levantamentos do que se conhece sobre um determinado assunto a partir de pesquisas realizadas em uma determinada área. $O$ estudo que aborda apenas um setor das publicações sobre o tema estudado vem sendo denominado de "estado do conhecimento".

2 Disponível em: <http://www.capes.gov.br/images/stories/download/avaliacaotrienal/Docs_de_area/Servi\%C3\%A7 o_Social_doc_area_e_comiss\%C3\%A3o_16out.pdf>. Acesso em: 06 de fev. de 2015.
} 


\section{DELINEAMENTO DA TEMÁTICA EDUCAÇÃO PROFISSIONAL E TECNOLÓGICA NOS PROGRAMAS DE PÓS-GRADUAÇÃO, STRICTO SENSU, EM SERVIÇO SOCIAL, SITUADOS NA REGIÃO CENTRO-OESTE}

No acervo digital das Instituições de Ensino Superior (IES) que ofertam cursos de pósgraduação, stricto sensu, em serviço social, situados na região Centro-Oeste, identificou-se que, os três programas totalizam 337 trabalhos defendidos entre dissertações e teses cadastradas. Com base nos títulos e resumos foram selecionadas as seis dissertações sobre a educação profissional e tecnológica.

As seis dissertações foram estudadas de acordo com as principais concentrações temáticas e temas abordados, priorizando mapear o título, autor, ano da defesa, tema, problema/objeto, referência teórica, base empírica/metodológica, sujeitos e conclusões/resultados, constituindo um delineamento dos vários núcleos de tendências relacionadas a essa modalidade de ensino. Os procedimentos metodológicos utilizados para a coleta de dados em cinco das dissertações analisadas são entrevistas semi-estruturadas e questionário (REIS, 2002; SILVA, 2009; MICHELI, 2010; SOBRINHO, 2013; GONÇALVES, 2014), sendo que em uma foi feita a análise documental (URBANO, 2013).

Os sujeitos das pesquisas são: a) egressos dos cursos profissionalizantes do CEFET-BA/ UNED-Barreiras e os empregadores das áreas técnicas (REIS, 2002, p. 16); b) adolescentes e jovens atendidas pela Casa da Juventude Pe. Burnier (SILVA, 2009, p. 47); c) gestores, servidores ativos e inativos dos IF's Goiás e Goiano, além dos onze assistentes sociais em exercício profissional, lotados nos diferentes campi dos institutos federais em Goiás (MICHELI, 2010, p. 26); d) gestores, estudantes usuários e profissionais responsáveis pela proposição e execução das principais ações realizadas pela Assistência Estudantil no IFG (SOBRINHO, 2013, p. 104); e) gestores, dirigentes, docentes e técnico-administrativos do IFG (GONÇALVES, 2014, p. 22).

Em cinco dissertações (REIS, 2002³; MICHELI, 2010; SOBRINHO, 2013; URBANO, 2013; GONÇALVES, 2014) as pesquisas de campo realizadas referem-se aos Institutos Federais e em uma (SILVA, 2009) reporta a Casa da Juventude Pe. Burnier, uma associação civil sem fins lucrativos.

Em quatro dissertações os estudos estão localizados na realidade do Estado de Goiás (SILVA, 2009; MICHELI, 2010; SOBRINHO, 2013; GONÇALVES, 2014); uma analisa a realidade do estado da Bahia (REIS, 2002) e outra a Rede CERTIFIC no plano nacional (URBANO, 2013).

O perfil profissional dos pesquisadores chama atenção, posto que os seis são assistentes sociais e com atuação profissional na área técnico-administrativa no local/IES pesquisada.

O caminho analítico percorrido, a partir da correlação de dados obtidos, culminou com o reconhecimento de três núcleos de tendências, que se interpenetram, e possibilitam aproximações as tendências na produção do serviço social sobre a educação profissional e tecnológica, em um movimento de articulação, visto que a educação não se desenvolve alheia às mudanças que se processam na ordem capitalista.

\footnotetext{
${ }^{3}$ No período da pesquisa, ano 2002, o Campus Barreiras do IF da Bahia, ainda era denominado CEFET-BA/ UNEDBarreiras.
} 


\section{EDUCAÇÃO PROFISSIONAL E TECNOLÓGICA: TENDÊNCIAS ANALÍTICAS}

\subsection{Reestruturação produtiva e a organização do trabalho no campo da educação profissional e tecnológica}

Uma abordagem sobre a educação profissional e tecnológica refere-se às consequências da reestruturação produtiva e os desafios da organização do trabalho nesse campo. Entende-se a educação profissional e tecnológica como uma área de estudos fundada nas relações capital e trabalho, justificando o reconhecimento e estudos das transformações socioeconômicas e políticas do capitalismo. Trata-se de uma perspectiva teórico-metodológica de compreensão do campo empírico, no qual as pesquisas se realizam.

Nessa tendência de análise, as mudanças ocorridas no mundo da produção, com o esgotamento do modelo taylorista/fordista e a transição para o padrão toyotista de produção e acumulação flexível do capital, apresentaram consequências significativas para o cenário educacional e perpassam as análises dos objetos de estudo.

Na dissertação "Análise da experiência dos egressos dos cursos profissionalizantes do CEFET Bahia Unidade de Barreiras" (REIS, 2002), a investigação sobre a educação profissional alude"à análise dos seus limites e de suas possibilidades enquanto criadora de oportunidades para inserção dos jovens no mercado de trabalho, no cenário atual de profundas transformações econômicas, sociais e políticas, tanto na esfera internacional quanto na nacional" (REIS, 2002, p. 13).

Para a autora, assistente social do Centro Federal de Educação Tecnológica da Bahia/UNEDBarreiras4, outro aspecto que não pode ser esquecido é que o desenvolvimento econômico tem se mostrado insuficiente para absorver o contingente de mão-de-obra disponível, "tornando na atualidade o desemprego e o subemprego uma questão de enorme gravidade, tornando-se um dos maiores desafios enfrentados tanto pelos países pobres quanto pelos ricos".

As análises de Silva (2009), na dissertação "A inserção da mulher jovem no mundo do trabalho e suas conexões com o processo de formação profissional", buscou "de forma crítica fazer um levantamento da inserção da mulher jovem no mundo do trabalho para dar visibilidade às reais condições do espaço laboral" (SILVA, 2009, p. 8). Para a autora, "é possível perceber que existe uma necessidade de formação/educação para engajamento no trabalho, e acompanhamento ao acelerado desenvolvimento do sistema capitalista (SILVA, 2009, p. 46)". O problema investigado incidiu sobre as dificuldades enfrentadas por mulheres jovens para inserirem-se no mundo do trabalho diante de uma realidade de precarização dos vínculos no espaço laboral.

Os estudos realizados por Urbano (2013), em sua dissertação "Reconhecimento $e$ certificação de saberes não formais na educação profissional de jovens e adultos: Análise política da política", examinam as implicações do contexto histórico, político e institucional sobre o processo de implantação da Rede CERTIFIC, no período de 2010 a 2012, nos Institutos Federais de Educação, Ciência e Tecnologia. Segundo a autora estes "assumem papel estratégico para a redução do analfabetismo e o aumento da qualificação profissional com elevação da escolaridade

\footnotetext{
${ }^{4}$ A partir da lei no 11.892, de 29 de dezembro de 2008, que institui a Rede Federal de Educação Profissional, Científica e Tecnológica e cria os Institutos Federais de Educação, Ciência e Tecnologia, passa a ser denominado IF da Bahia Campus Barreiras.
} 
de trabalhadores jovens e adultos que se encontram à margem do mercado de trabalho" (URBANO, 2013, p. 15).

Consoante Urbano (2013), o neoliberalismo e a reestruturação produtiva da era da acumulação flexível, "dotadas de forte caráter destrutivo, têm acarretado, entre tantos aspectos devastadores, o desemprego, uma enorme precarização do trabalho e uma degradação crescente, na relação entre homem e natureza, conduzida pela lógica de sociedade voltada prioritariamente para a produção e consumo de mercadorias" (URBANO, 2013, p. 39).

Nesse contexto, Urbano (2013) analisa que, a partir da década de 1990 do século XX, realizaram-se uma série de reformulações nas políticas de Educação Profissional no Brasil, no intuito de estabelecer relações favoráveis às mudanças necessárias ao padrão de acumulação dos países periféricos, tornando os trabalhadores "adaptáveis" e "receptivos" a elas. Portanto, é nesse momento que o discurso e o ideário da empregabilidade se destaca, já que mais do que pensar a integração dos trabalhadores ao mercado de trabalho, as políticas educacionais devem orientarse para garantir a transmissão diferenciada de competências flexíveis capazes de habilitarem os trabalhadores para lutar pelos poucos empregos disponíveis.

Em "Política Nacional de Educação Profissional: O alcance da assistência estudantil no Instituto Federal De Educação, Ciência e Tecnologia de Goiás - 1990 a 2012", Sobrinho (2013) assistente social do IF Goiás Campus Inhumas, analisa que, as transformações determinadas pela reestruturação produtiva passaram a exigir do ensino profissionalizante a formação de um egresso capaz de atender às demandas da revolução na base técnica de produção, o que acarretou profundos impactos na vida social. "Atualmente, o objetivo a ser atingido é a capacidade para lidar com a incerteza, substituindo a rigidez pela flexibilidade e rapidez, de modo a atender a demandas dinâmicas, que se diversificam em qualidade e quantidade" (SOBRINHO, 2013, p. 55). De acordo com Sobrinho (2013), a educação profissional no governo Luiz Inácio da Silva "representou o continuísmo de um Estado burguês que sempre marcou o sistema político do país" (p. 63).

Na dissertação "A expansão da Rede de Educação Profissional, Científica e Tecnológica: Implicações nas relações e condições de trabalho no Instituto Federal de Educação, Ciência e Tecnologia de Goiás" tem-se uma análise dos complexos fenômenos relativos às mudanças contemporâneas. Assim como, a relação destas com as transformações recentes ocorridas no modo de produção capitalista, "marcadas pela transição do modelo keynesiano-fordista para o modelo pós-fordista/toyotista e como essas mudanças repercutem na contrarreforma do Estado brasileiro e nas políticas de educação profissional” (GONÇALVES, 2014, p. 20-21).

De acordo com Gonçalves (2014), nessa configuração, os trabalhadores que atuam nos institutos federais participam em diversas frentes de trabalho por meio de um amplo leque de níveis e modalidades ofertados por essas autarquias. Conforme a autora, verifica-se aumento da flexibilização do trabalho, conduzindo a um aumento e diversificação do trabalho prescrito. Intensifica-se o trabalho com exigências de realização de mais trabalho e resultados superiores no mesmo espaço de tempo, em razão do crescente aumento do número de vagas, de programas, de várias disciplinas a serem ministradas em diferentes cursos técnicos, dos programas e modalidades de ensino (integrado, subsequente, concomitante, superior, pós-graduação a distância, Proeja, Pronatec, Mulheres Mil, dentre outros), provenientes do projeto governamental e que são executados pelas instituições. 
As análises de Micheli (2010), em "Processo histórico do serviço social em Institutos Federais de Educação, Ciência e Tecnologia no estado de Goiás: dimensões da prática profissional do assistente social - 1989 a 2009", recaíram sobre o processo de reflexão e de desvelamento da prática profissional do assistente social nos institutos federais, visto que "assume relevância social, em particular, no delicado momento de intensas e aceleradas mudanças estruturais ocorridas no mundo do trabalho que impõem desafios à implementação do projeto ético-político do Serviço Social e às perspectivas futuras da educação profissional e tecnológica no Brasil" (MICHELLI, 2010, p. 15). Na conclusão de sua pesquisa a autora enfatiza a importância de se apreender o real significado das transformações sociais em curso, fortalecendo a direção social estratégica assumida pelas vanguardas do Serviço Social, rumo à consolidação do projeto societário que preconiza a democracia igualitária, a justiça redistributiva e a emancipação humana dos sujeitos históricos (MICHELLI, 2010, p. 165).

Essa tendência analítica é corroborada pela pesquisa efetuada por lamamoto (2007), na qual foram utilizados os resultados da Avaliação Trienal dos Programas de Pós-graduação da Capes/MEC (2001-2003), realizada em 2004, verifica-se que, "o tema trabalho alcançou a segunda posição na prioridade da pesquisa, condizente com as transformações societárias operadas na esfera da produção e dos mercados no atual estágio de acumulação capitalista" (IAMAMOTO, 2007, p. 460).

\title{
4.2 Educação e dualidade estrutural
}

Os estudos de quatro dissertações (REIS 2002; SOBRINHO, 2013; URBANO, 2013; GONÇALVES 2014) possibilitaram situá-las como representativas de análises sobre a educação profissional e tecnológica como um processo que engendra e recria relações sociais de classe.

Reis (2002) avalia que, a formação de trabalhadores e cidadãos no Brasil se constituiu historicamente com base na estratégia da dualidade:

\begin{abstract}
No governo do presidente Nilo Peçanha, através do decreto no 7.566 de 23 de outubro de 1909, são criadas nas capitais dos estados da república as escolas de aprendizes e artífices, voltadas para a prestação do ensino profissional primário e gratuito, destinado aos pobres e humildes, assumindo uma perspectiva assistencialista e de dualidade, ou seja, enquanto aos filhos da burguesia era oferecido o ensino propedêutico - o que se traduzia numa educação que lhes garantia uma posição de mando na estrutura social —; aos filhos dos pobres era destinada a formação profissional que lhes possibilitasse a inserção na estrutura produtiva (REIS, 2002, p. 26, grifo do autor).
\end{abstract}

A análise de Gonçalves (2014) destaca que, a correlação de forças travada no âmbito da política de educação, que define a permanência ou a superação da dualidade educacional, ultrapassa regimes ditatoriais e democráticos, governos civis e militares. $E$, em cada contexto sócio-histórico essa disputa é materializada em documentos legais como constituições, leis orgânicas e decretos, os quais evidenciam interesses econômicos, político-pedagógicos, e ideopolíticos em disputa. Segundo a autora, as reformulações da política expansionista da educação profissional, iniciadas na década de 1990, manifestaram um continuísmo das ações educacionais, sobretudo, no aprofundamento da dualidade educacional e estrutural, precarização do ensino e das condições de trabalho, e ainda, a privatização, mercantilização e tecnificação do ensino e 
retorno da teoria do capital humano, com a instituição do Programa Nacional de Acesso ao Ensino Técnico e ao Emprego (Pronatec) - Lei no 12.513/2011 (GONVALVES, 2014, p. 69).

Ideias que corroboram as análises de Urbano (2013, p. 144). De conformidade com a autora:

A chamada reforma da educação profissional, realizada sob a alegação de expandir, diversificar e flexibilizar a oferta, visou à constituição de um sistema de formação específico e à promoção de modalidades educativas substitutas ou alternativas à educação básica e superior, acentuando a dualidade estrutural e a segmentação social da educação nacional.

Disso depreende-se Gonçalves (2014) que a "dualidade educacional entre o ensino médio e a educação profissional não é uma problemática só conjuntural, mas também estrutural que, na história brasileira, se expressa pela reprodução das relações de desigualdades entre as classes sociais, tendo em vista que a imensa desigualdade educacional é uma das formas de manifestação" (GONÇALVES, 2014, p. 58).

Sobrinho (2013) ressalta que, o acentuado índice de desigualdade social da sociedade brasileira torna difícil a superação da dualidade estrutural refletida na área educacional e nas demais áreas. Para o autor, o desafio para superar a dualidade torna-se maior quando se sabe que a dualidade estrutural da educação tem suas raízes na forma de organização da sociedade expressa nas relações contraditórias entre capital e trabalho. No entanto, há que se reconhecer que, a formação básica profissionalizante precisa enfrentar os desafios apresentados, identificando as suas verdadeiras causas, para que se possam propor medidas adequadas (SOBRINHO, 2013, p. 30).

Essa tendência analítica demonstra as aproximações entre a teorização crítica na área de serviço social e na área da educação. Ciavatta e Ramos(2011) consideram que, o fator mais importante nessa análise é "proceder à análise das raízes sociais da questão, a questão estrutural das classes sociais que lhe dão sustentação e sua ideologização como educação desejável, segundo as autoras, o risco do uso do conceito de 'dualidade educacional', sem a identificação das particularidades históricas da totalidade do processo "conduz ao abandono da dialética, das mediações e contradições dos fenômenos sociais" (CIAVATTA E RAMOS, 2011, p. 29).

\subsection{Políticas sociais e assistência estudantil}

Para a composição deste núcleo de tendências analíticas relacionadas à educação profissional e tecnológica, os dados das seis dissertações possibilitaram estabelecê-las como representativas de análises sobre a produção discente da pós-graduação em serviço social, situadas na região Centro-Oeste. Segundo lamamoto (2007, p. 459), "é conhecida a concentração da pesquisa no eixo das relações entre Estado e a sociedade civil no âmbito das políticas públicas - em especial das políticas sociais - terreno contraditório em que se inscreve majoritariamente a atuação do assistente social em resposta às expressões da questão social".

Gonçalves (2014, p. 29) afirma que ao analisar a relação trabalho, educação e políticas públicas, devem ser consideradas as tensões e as contradições e intencionalidades que perpassam a relação entre Estado e sociedade, a fim de elucidar as múltiplas expressões da questão social e as respostas do Estado para o seu enfrentamento. Conforme Sobrinho (2013, p.126), a educação profissional, para realizar-se como política pública, precisa estabelecer interfaces com a assistência 
social no desenvolvimento de projetos socioassistenciais voltados para as necessidades básicas dos estudantes, filhos de famílias de baixa renda, com o objetivo não só de acessarem o ensino superior e os cursos técnicos, mas de permanecerem na instituição até a conclusão de seus cursos.

Ao investigar especificamente a assistência estudantil, Sobrinho (2013, p. 65) afirma ser "uma política social institucional, que deve se voltar para a atenção às necessidades sociais básicas, e não mínimas, dos estudantes que demandam seus serviços e programas". Além de ser uma estratégia de que a instituição se apropria para possibilitar as condições de permanência e inclusão, por meio da implementação de programas sociais, tendo em vista a superação das dificuldades encontradas por esses alunos em seu itinerário formativo. $\mathrm{O}$ autor chama a atenção para a regulamentação do Programa Nacional de Assistência Estudantil (BRASIL, Pnaes, 2010), que "constitui um marco legal regulatório da assistência estudantil implementada nas instituições federais de ensino em todo país, incluindo os institutos federais" (SOBRINHO, 2013, p. 125).

Micheli (2010, p. 111) também examina a política de assistência estudantil. Segundo a autora, no tocante a essa realidade, torna-se ainda maior o desafio apresentado para os profissionais da educação, sobretudo do serviço social, que objetivam contribuir para a democratização do acesso e permanência nas instituições de ensino daqueles que vivem de seu próprio trabalho. O que pressupõe incrementar, tanto a política de assistência estudantil, como a luta em defesa do ensino gratuito, como um bem público e de qualidade, para o maior número possível de estudantes trabalhadores.

Para Micheli (2010), a concepção de assistência social estudantil não pode ser reduzida ao repasse de auxílios materiais, ainda que necessários, uma vez que essas medidas, quando isoladas, comprometem seriamente a secular vinculação da assistência com o conceito de pobreza absoluta.

Outro debate importante nesse processo, segundo a referida autora, é a identificação das interfaces existentes entre a política de educação, sobretudo a profissional e tecnológica, com as demais políticas públicas e de direito, como as de assistência social, emprego, renda e saúde, dentre outras, considerando os índices de pobreza, desemprego e desigualdade social, bem como os indicadores de saúde, ainda presentes no Brasil (p. 111).

Análises semelhantes são desenvolvidas por Silva (2009), apontando que "a consolidação de políticas sociais para a juventude que assegurem as condições objetivas de formação profissional e inserção no mercado de trabalho, como possibilidade de tecer as mudanças na realidade sócio familiar, indicada pelas entrevistas como novas condições de vida" (p. 64).

Reis (2002) ao término de seu estudo afirma que a educação profissional de qualidade representa uma verdadeira oportunidade de melhoria de vida para os segmentos populares em nossa sociedade. No entanto, a efetividade dessa política pode ser potencializada, mediante sua articulação com as demais políticas setoriais, sobretudo, as de natureza socioeconômica, no que tange à necessidade de geração de emprego e renda.

\section{CONSIDERAÇÕES FINAIS}

O percurso teórico-metodológico desenvolvido na pesquisa evidenciaram que os estudos sobre a temática da educação profissional e tecnológica enfatizaram as análises sobre as profundas transformações econômicas, sociais, políticas e culturais, que marcaram o capitalismo contemporâneo e os parâmetros para uma apreensão das suas expressões na realidade brasileira. 
São estudos e produção de conhecimentos que vão além do esboço sobre o modo como essas transformações contemporâneas do capitalismo tiveram consequências para o campo da educação profissional e tecnológica.

Nessa perspectiva as aproximações analíticas sistematizadas: reestruturação produtiva e a organização do trabalho no campo da educação profissional e tecnológica, educação e dualidade estrutural e políticas sociais e a assistência estudantil, atestam que, nos trabalhos analisados os autores negam, aprofundam e superam as formas e manifestações aparentes dos processos e relações sociais, o que exigiu fundamentação teórico-metodológica que permitisse aos pesquisadores a análise crítica, sobretudo nas abordagens sobre o capitalismo contemporâneo, suas expressões e complexidade, nos ensaios de desvelamento da aparência que recobre a realidade. E continuarão exigindo maiores aprofundamentos, recuperando e relacionando outras expressões presentes nas dissertações, quanto ao embricamento entre o público e o privado na educação profissional e tecnológica, o ensino médio integrado e a importância deste como etapa final da educação básica, necessária ao domínio de uma base de conhecimentos para a compreensão da complexa sociedade em que vivemos, entre outras.

Em síntese o estudo desenvolvido confirma que a temática educação profissional e tecnológica ganha relevância no Serviço Social com as transformações e recomposições do capitalismo e as correlatas mudanças na organização do trabalho, período que coincide com as novas configurações nas políticas educacionais do Estado brasileiro, a expansão da pós-graduação no Brasil e o desenvolvimento de um novo campo de estudos, pesquisa e produção de conhecimento, que, de maneira mais geral, trata da relação entre o sistema produtivo e o sistema educativo, como mediações essenciais na relação trabalho e educação.

\section{REFERÊNCIAS}

1. BRASIL. Ministério da Educação (MEC). Coordenação de Aperfeiçoamento de Pessoal de Nível Superior (Capes). Avaliação da pós-graduação. 2010-2012. COUTO, Berenice R. et al. Documento de área 2013. Serviço Social e Economia Doméstica. Brasília, out. 2013.

2. CIAVATTA. RAMOS, Marise. Ensino médio e educação profissional no Brasil: dualidade e fragmentação. Retratos da Escola.Escola de Formação da Confederação Nacional dos Trabalhadores (Esforce). Brasília, v. 5, n. 8, jan/jun. 2011.

3. Ensino médio e educação profissional no Brasil: dualidade e fragmentação. Retratos da Escola, Brasília, v. 5, n. 8, p. 27-41, jan/jun. 2011.

4. . TREIN, Eunice O percurso teórico e empírico do GT Trabalho e Educação. Uma análise para debate. Revista Brasileira de Educação, Rio de Janeiro, n.24 set /dez. 2003.

5. GONÇALVES, Sandra L. A Expansão da Rede de Educação Profissional, Científica e Tecnológica: Implicações nas relações e condições de trabalho no Instituto Federal de Educação, Ciência e Tecnologia de Goiás. 2014. Dissertação (Mestrado em Serviço Social). Pontifícia Universidade Católica de Goiás (PUC Goiás), Goiânia.

6. IAMAMOTO, Marilda V. Serviço Social em tempo de capital fetiche: capital, financeiro, trabalho e questão social. São Paulo, Cortez, 2007.

7. KOSIK, Korel. Dialética do concreto. Rio de Janeiro: Paz e Terra, 1985. 
8. MICHELI, Altair J. de C. Processo histórico do Serviço Social em Institutos Federais de Educação, Ciência e Tecnologia no Estado de Goiás: dimensões da prática profissional do assistente social - 1989 a 2009. 2010. Dissertação (Mestrado em Serviço Social) - Pontifícia Universidade Católica de Goiás (PUC Goiás). Goiânia.

9. REIS, Cacilda F. dos. Análise da Experiência dos Egressos dos Cursos Profissionalizantes do CEFET-Bahia Unidade de Barreiras. 2002. Dissertação (Mestrado em Política Social) Universidade de Brasília (UnB). Brasília.

10. ROMANOWSKI, Joana Paulin. ENS, Romilda Teodora. As pesquisas denominadas do tipo "estado da arte" em educação. Diálogo Educ., Curitiba, v. 6, n.19, p.37-50, set./dez. 2006.

11. SILVA, Josiane E. da. A inserção da mulher jovem no mundo do trabalho e suas conexões com o processo de formação profissional. 2009. Dissertação (Mestrado em Serviço Social) Pontifícia Universidade Católica de Goiás (PUC Goiás). Goiânia.

12. SOBRINHO, Olinto B. Política nacional de educação profissional: o alcance da assistência estudantil no IFG - 1990 a 2012. 2013. Dissertação (Mestrado em Serviço Social) - Pontifícia Universidade Católica de Goiás (PUC Goiás). Goiânia.

13. URBANO, Fernanda S. de S. Reconhecimento e certificação de saberes não formais na educação profissional de jovens e adultos: análise política da política. 2013. Dissertação (Mestrado em Política Social) - Universidade Federal do Mato Grosso (UFMT). Cuiabá. 